\title{
SISTEM INFORMASI PENYEWAAN DVD PADA RENTAL DVD CHASS MERAUKE
}

\section{Agus Prayitno, Izak Wayangkau, Try Adrianto Darsono}

Email : agusprayitno@unmus.ac.id,izak@unmus.ac.id, adidarsono@unmus.ac.id

\author{
Jurusan Teknik Informatika, Fakultas Teknik \\ Universitas Musamus Merauke
}

\begin{abstract}
ABSTRAK
Manajemen pengolahan data yang berjalan pada Rental DVD CHASS selama ini masih dilakukan secara manual, masalah-masalah yang sering ditemui pada Rental DVD CHASS saat ini yaitu, pelanggan melakukan pemilihan beberapa koleksi yang ada pada buku daftar koleksi yang telah disediakan pemilihan tersebut dilakukan dengan melihat judul atau kode koleksi, pelanggan tidak dapat mencari berdasarkan kode film, judul atau jenis koleksi yang diinginkan.

Perancangan sistem menggunakan teknik DFD dan pembuatan sistem menggunakan aplikasi Visual Studio Versi 2008 dengan menggunakan database SQL Server 2000.

Sistem Informasi Penyewaan DVD Pada Rental DVD CHASS dapat membantu dalam proses pencarian data koleksi dan pelaporan data koleksi, tampilan program ini dibuat sederhana dengan prinsip kemudahan dalam pembacaan data. Hasil akhir dari sistem ini adalah manajemen dan pelaporan yang akurat.
\end{abstract}

Kata kunci : Memilih judul film, Database, Manajemen dan Laporan.

\section{PENDAHULUAN}

Teknologi komputer sangat berperan penting dalam seluruh kegiatan manusia dan telah banyak memberikan kemajuan dan peningkatan efisiensi kinerja agar menjadi lebih akurat.

Manajemen pengolahan data yang berjalan pada Rental DVD CHASS selama ini masih dilakukan secara manual, masalah-masalah yang sering ditemui pada Rental DVD CHASS saat ini yaitu :

a. Pelanggan melakukan pemilihan beberapa koleksi yang ada pada buku daftar koleksi yang telah disediakan pemilihan tersebut dilakukan dengan melihat judul atau kode koleksi.

b. Pelanggan tidak dapat mencari berdasarkan kode film, judul atau jenis koleksi yang diinginkan.

c. Pelanggan harus menulis beberapa kode DVD yang ingin dipesan, hal ini terjadi karena pengelola tidak dapat mengingat apabila koleksi yang dipinjam terlalu banyak, untuk melayani pelanggan, petugas harus mengetahui kode pelanggan yang telah melakukan pemesanan tersebut, kemudian petugas tidak dapat mengkoordinir pelanggan mana yang telah melakukan pemesanan lebih awal apabila jumlah pelanggan yang melakukan pemesanan sudah banyak.

Berdasarkan latar belakang di atas, maka diperlukan suatu perancangan Sistem Informasi Penyewaan DVD pada Rental DVD CHASS Merauke yang dapat digunakan dalam proses penyewaan dan pengeluaran DVD, penulis tertarik untuk mengambil judul : "SISTEM INFORMASI PENYEWAAN DVD PADA RENTAL DVD CHASS MERAUKE".

\section{RUMUSAN MASALAH : \\ Latar belakang masalah yang telah diuraikan di atas maka dirumuskan permasalahan yaitu, Bagaimana membuat desain suatu Sistem Informasi Penyewaan Pada Rental DVD CHASS Merauke, agar dapat mempermudah dalam pencarian data koleksi, data kerusakan DVD, data jumlah pendapatan dan pelaporan data koleksi, pelaporan data kerusakan, pelaporan data jumlah pendapatan.}




\section{TUJUAN PENELITIAN :}

1. Membuat desain suatu sistem informasi manajemen pada Rental DVD CHASS agar dapat mengembangkan usaha penyewaan DVD dalam masyarakat.

2. Melakukan penerapan sistem informasi penyewaan DVD pada Rental DVD CHASS dan pada masyarakat sekitar agar Rental DVD CHASS menjadi pusat perhatian khususnya bagi penyewaan DVD.

\section{TINJAUAN PUSTAKA}

Sistem informasi geografis ini sebelumya sudah banyak di buat, tetapi tempat dan program aplikasinya yang di gunakan berbedabeda. Adapun sistem informasi geografis adalah sebagai berikut :

Mohammad Ali (2004) : “ Sistem Komputerisasi Penyewaan VCD Pada Venus Rental Merauke ". Penelitian Mohammad Ali dapat memberikan pemahaman baru kepada masyarakat khususnya pengusaha jasa penyewaan VCD bahwa saat ini penggunaan sistem komputerisasi dapat membantu mempercepat menangani setiap proses yang berlangsung di tempat kerja, mulai dari penginputan data, proses penyimpanan data dan sampai pada proses pembuatan laporan yang dibutuhkan pengguna.

\section{PENGERTIAN SISTEM}

Terdapat dua kelompok dalam mendefinisikan sistem, yaitu yang menekankan pada prosedurnya dan menekankan pada komponen atau elemennya. Sedangkan sistem yang lebih menekankan pada elemen atau komponennya mendefinisikan bahwa sistem adalah kumpulan dari elemen elemen yang saling berinteraksi untuk mencapai suatu tujuan tertentu. Sistem dapat berarti sebagai sekelompok elemen yang terintegrasi dengan maksud yang sama untuk mencapai suatu tujuan (McLeod R, Jr. 1998).

Sistem informasi adalah suatu kegiatan dari prosedur yang diorganisasikan bilamana dari eksekusi akan menyediakan informasi untuk mendukung pengambilan keputusan dan pengendalian dari dalam organisasi" pernyataan (Davis GB. 2001).

\section{ANALISIS SISTEM}

Analisis sistem adalah mempelajari suatu masalah dan mempunyai tujuan utama untuk melakukan tindakan. Analisis sistem adalah proses menentukan kebutuhan apa-apa yang harus dilakukan sistem untuk memenuhi kebutuhan klien, bukanlah bagaimana sistem tersebut diimplementasikan. (De Marco, 1996).

\section{METODE PENELITIAN}

Metode yang digunakan dalam penelitian ini adalah sebagai berikut:

\section{METODE PENGUMPULAN DATA}

1. Studi Pustaka

Studi pustaka dilakukan dengan cara mempelajari teori-teori literatur dan buku-buku yang berhubungan dengan obyek sebagai dasar dalam penelitian.

2. Observasi

Teknik pengumpulan data dengan mengadakan penelitian dan peninjauan langsung terhadap permasalahan yang diambil.

3. Interview

Teknik pengumpulan data dengan mengadakan tanya jawab secara langsung yang ada kaitannya dengan topik yang diambil.

\section{PERANCANGAN}

$$
\begin{aligned}
& \text { Perancangan Yaitu melakukan } \\
& \text { perancangan program yang akan } \\
& \text { diinformasikan dengan. } \\
& \text { a. Data Flow Diagram (DFD). } \\
& \text { b. Perancangan antarmuka (interface). } \\
& \text { c. Perancangan database pada sistem atau } \\
& \text { aplikasi website yang dibuat. }
\end{aligned}
$$

2. Analisa data yaitu melakukan analisa data dengan menggunakan kuisoner untuk menguji program yang dibuat

3. Pengujian

Pengujian dilakukan dengan Metode Black Box dengan menggunakan kuisioner.

\section{PERANCANGAN SISTEM}

Tahapan ini akan dilakukan perancanagn pemodelan fungsional sistem secara keseluruhan. Dapat digambar sebagai berikut:

\section{DIAGRAM KONTEKS}

Proses perancanagan dimulai dengan pembuatan Diagram Konteks. Diagram 
Konteks menggambarkan suatu sistem secara global dan sederhana.

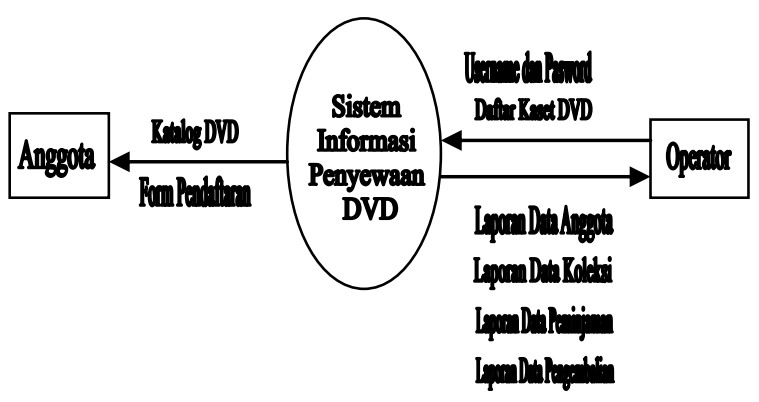

Gambar. Rancangan diagram konteks

\section{IMPLEMENTASI DAN PENGUJIAN SISTEM}

IMPLEMENTASI

Implementasi sistem merupakan tahap meletakkan sistem supaya siap untuk dioperasikan. Tahap implementasi sistem diantaranya adalah menerapkan rencana implementasi, melakukan kegiatan implementasi dan tindak lanjut implementasi”.(Jogiyanto, 2001)

Pengoperasian Program

Interface menu utama merupakan tampilan awal pada saat program pertama kali dibuka. Dalam interface menu utama berisi menu-menu diantaranya adalah Home ,Informasi Karet, Kontak, Peta dan admin. Untuk menu user merupakan login langsung penggunaan program, dan menu admin merupakan menu masuk program yang memiliki password.

Berikut ini langkah-langkah untuk mengoperasikan program sistem informasi penyewaan kaset DVD :

1. Klik dua kali pada file exe program ini.

2. Terdapat Pemberitahuan sebelum masuk ke menu login

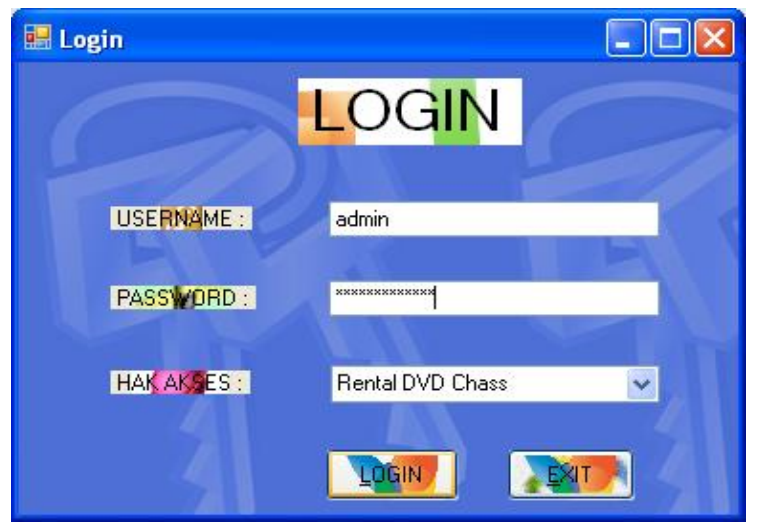

\section{Gambar. Menu Login}

Setelah berhasil melakukan proses login, menu yang akan tampil adalah menu utama yang mempunyai beberapa menu yaitu login, entry, cari, laporan anggota, koleksi, peminjaman, pengembalian dan keluar.

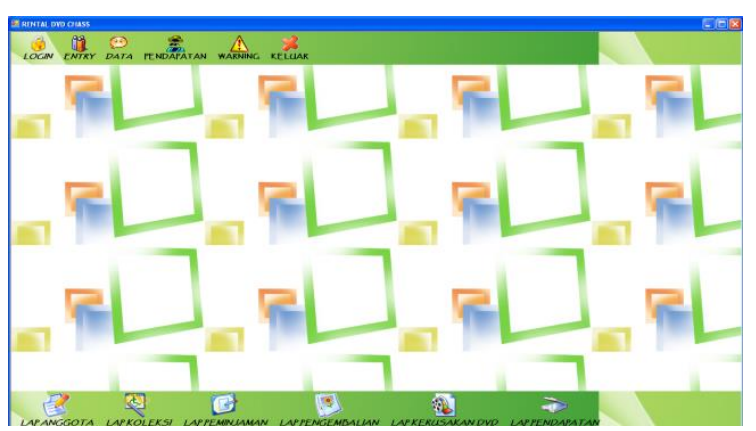

Gambar. Menu Utama

Menu entry anggota digunakan untuk mencatat data konsumen yang melakukan pendaftaran penyewaan kaset DVD.

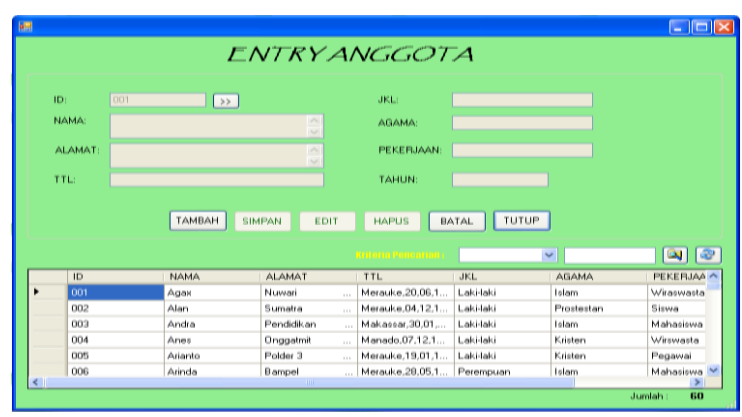

Gambar. Form Entry Anggota

Proses transaksi peminjaman ini digunakan untuk mencatat data transaksi penyewaan DVD.

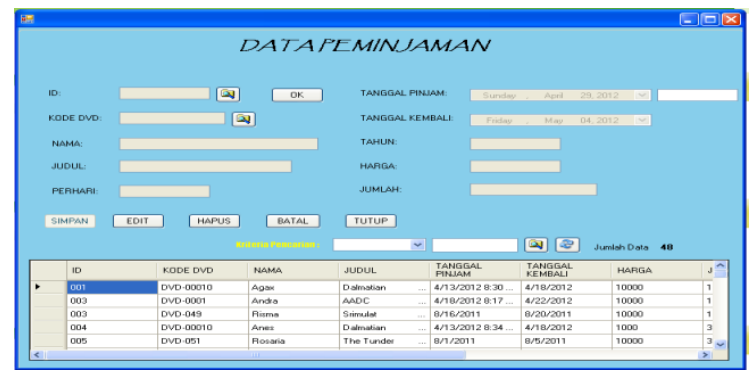

Gambar. Form Transaksi Peminjaman

Proses transaksi pengembalian ini digunakan untuk mencatat data transaksi penyewaan DVD. 


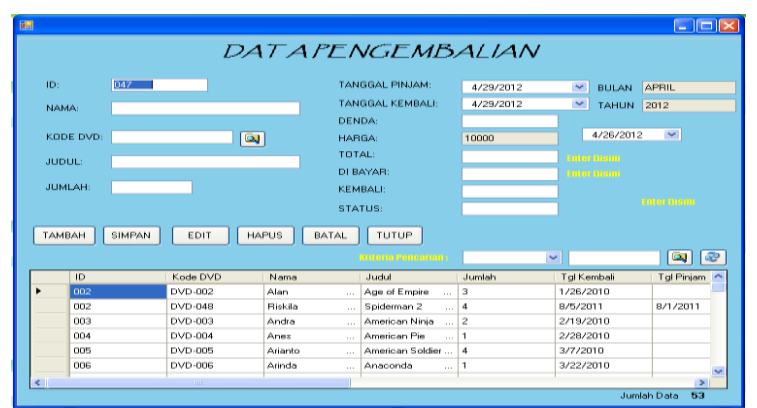

Gambar. Form Transaksi Pengembalian

Form laporan data anggota digunakan untuk melihat data anggota penyewaan DVD.

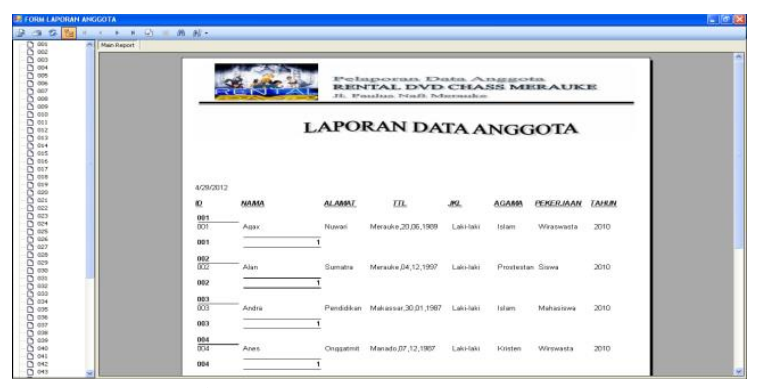

Gambar. Laporan Data Anggota

Laporan data koleksi digunakan untuk melihat judul dan kode DVD.

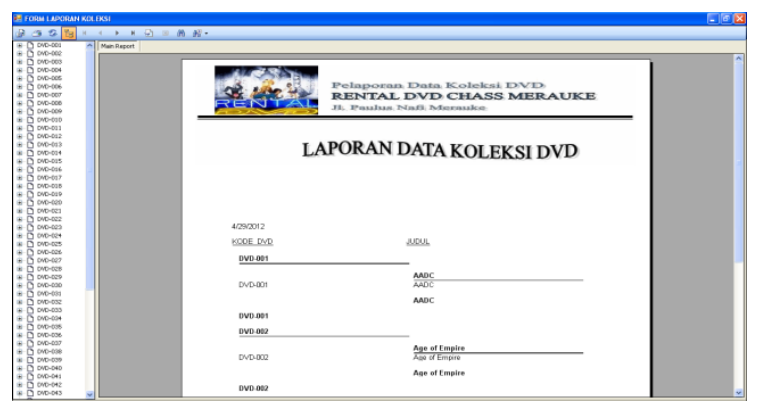

Gambar. Laporan Data Koleksi

Laporan data peminjaman dalam bentuk bulanan dan tahunan digunakan untuk melihat anggota yang telah meminjam DVD.

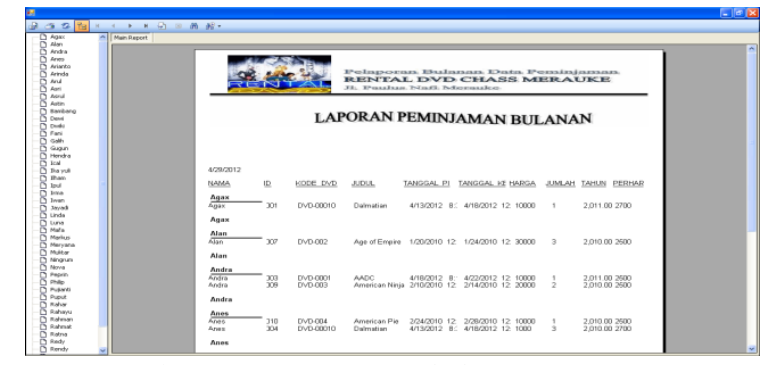

Gambar. Laporan Peminjaman Laporan

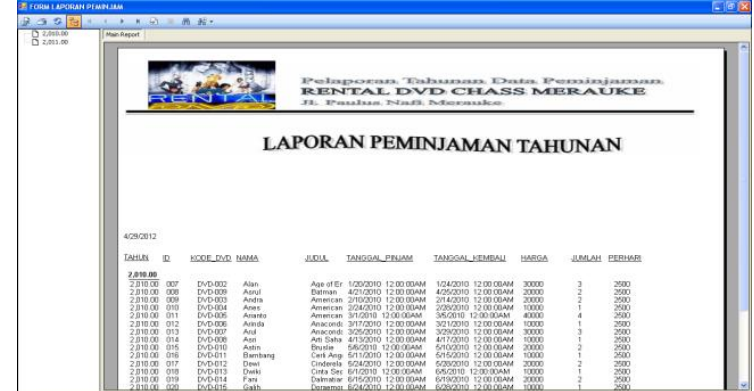

Gambar. Laporan Peminjaman Tahunan

\section{PENGUJIAN}

Pengujian sistem dilakukan untuk mendefinisikan kesalahan program yang diakibatkan oleh kesalahan logika program sehingga terjadi penghentian program secara tidak normal. Pengujian sistem ini dilakukukan dalam dua cara yaitu pengujian Black Box dan Kuisioner.

\section{PENGUJIAN BLACK BOX}

Pengujian Black Box bertujuan untuk menguji komponen sistem yang telah dirancang sebelumnya dan untuk memastikan bahwa setiap elemen dari sistem telah berfungsi sesuai dengan yang diharapkan.

Pengujian yang berfokus pada persyaratan atau kebutuhan perangkat lunak yang dibuat.

Hasil uji coba mengenai kemudahan dalam menginput data pada pogram :

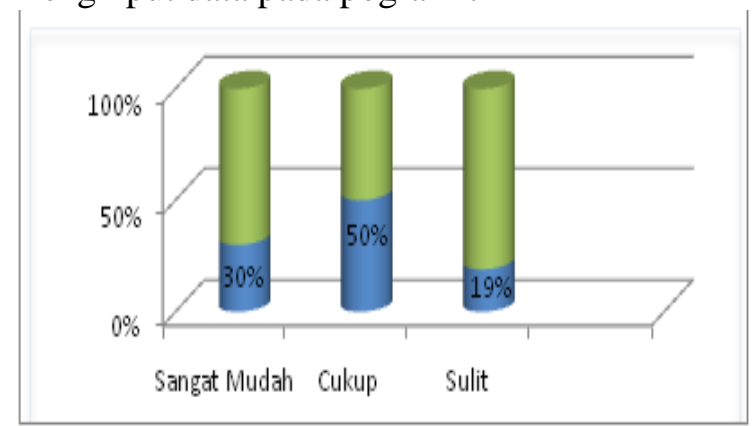

Gambar. Hasil pengujian kemudahan input data

Berdasarkan hasil wawancara tentang kemudahan dalam menginputkan data pada program diperoleh informasi sebagai berikut, 1 (30\%) narasumber menjawab sangat mudah, 1 (50\%) narasumber menjawab cukup mudah, dan 1 (19\%) narasumber menjawab Sulit. 
Hasil uji coba mengenai kemudahan dalam pencarian data :

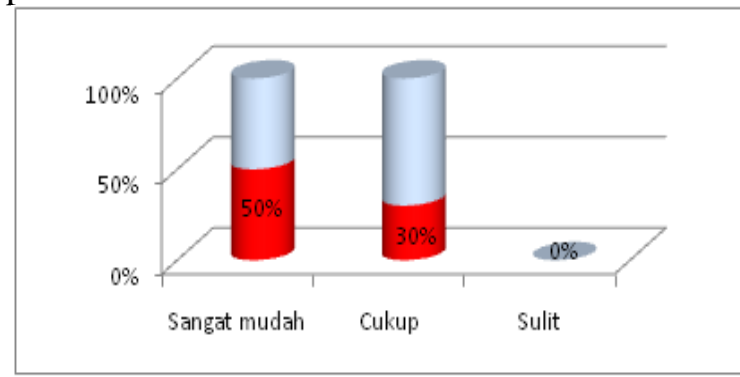

Gambar. Hasil pengujian pencarian data

Berdasarkan hasil wawancara tentang kemudahan dalam pencarian data pada program diperoleh informasi sebagai berikut, 1 (50\%) narasumber menjawab sangat mudah, 2 (30\%) narasumber menjawab cukup mudah dan tidak ada yang narasumber menjawab sulit.

Hasil uji coba mengenai Kompleksitas data dan informasi :

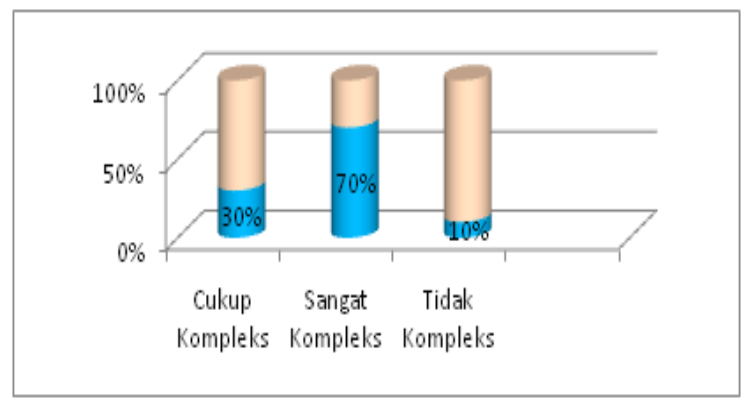

Gambar. Hasil pengujian kompleksitas informasi

Berdasarkan hasil wawancara tentang kompleksitas data dan informasi pada program diperoleh informasi sebagai berikut, 1 (30\%) narasumber menjawab cukup kompleks, 1 $(70 \%)$ narasumber menjawab sangat kompleks, dan 1 (10\%) narasumber menjawab tidak kompleks.

Hasil uji coba mengenai Kemudahan dalam mengakses informasi :

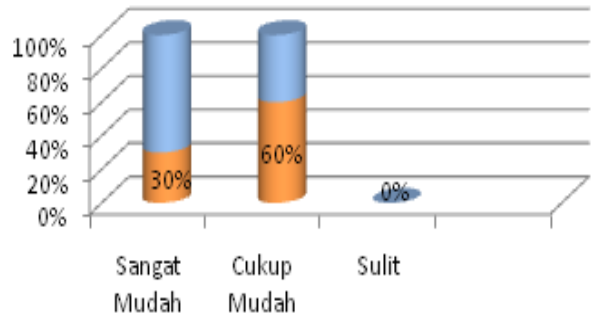

Gambar. Hasil pengujian kemudahan mengakses informasi
Berdasarkan hasil wawancara tentang kemudahan dalam mengakses data dan informasi diperoleh informasi sebagai berikut, $2(60 \%)$ narasumber menjawab sangat mudah, 1 (30\%) narasumber menjawab cukup mudah dan tidak ada responden yang menjawab sulit.

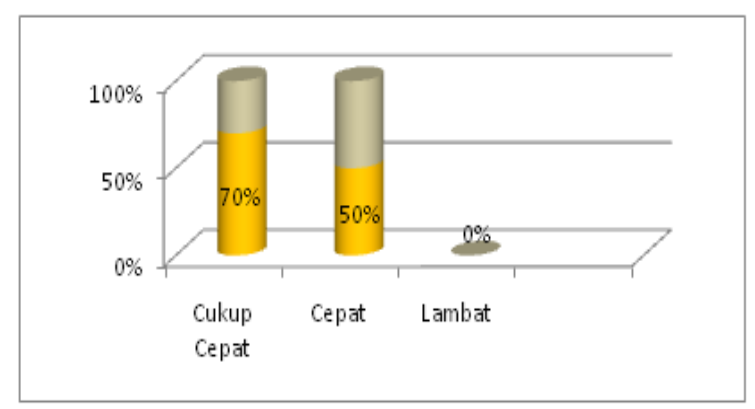

Hasil uji coba mengenai Kecepatan akses dalam menampilkan data informasi :

Gambar. Hasil pengujian kecepatan menampilkan data

Berdasarkan hasil wawancara tentang kecepatan akses data dan informasi diperoleh data sebagai berikut, $2(70 \%)$ narasumber menjawab cukup cepat, $1(50 \%)$ narasumber menjawab cepat dan tidak ada responden yang menjawab lambat.

Hasil uji coba Mengenai Bagaimana tentang sistem ini secara keseluruhan:

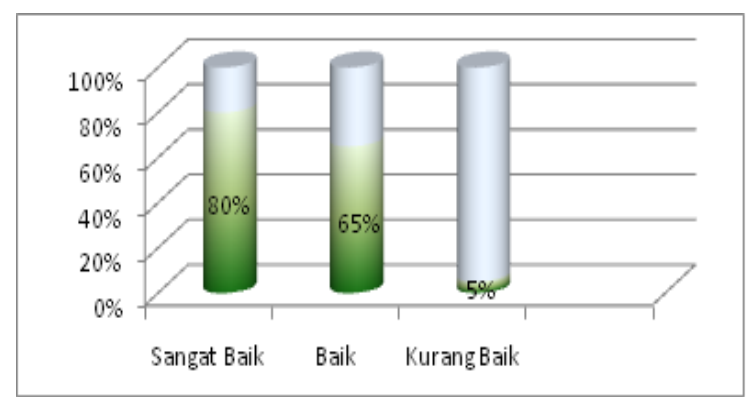

Gambar. Hasil pengujian sistem secara keseluruhan

Berdasarkan hasil wawancara tentang sistem secara keseluruhan diperoleh informasi sebagai berikut, $1(80 \%)$ narasumber menjawab sangat baik, $1(65 \%)$ narasumber menjawab baik dan 1 $(5 \%)$ narasumber menjawab kurang baik.

\section{PENUTUP}

\section{KESIMPULAN}

Perancangan sistem ini menggunakan Microsoft Visual Studio Versi 2008 dengan sumber data yang diambil pada tahun 2010 sampai 2011 dan perancangan sistem ini tidak membahas tentang sistem pelaporan peminjaman DVD, yaitu dapat mempermudah dalam pencarian data koleksi ditunjukan pada 
gambar 4.7 dan pelaporan data koleksi ditunjukan pada gambar 4.14 pada bab IV, tampilan program ini dibuat sederhana dengan prinsip kemudahan dalam pembacaan data.

\section{SARAN}

Masih ada beberapa permasalahan dalam penelitian ini yang belum terselesaikan berhubung keterbatasan waktu. Sejumlah perasalah yang belum terselesaikan ada 3 yaitu sistem berbasis jaringan peer to peer, laporan persewaan yang lebih terinci dan penyewaan DVD berbasis online yang tidak termasuk dalam penelitian ini untuk direkomendasikan kepada Penelitian selanjutnya dan mengembangkan teknologi dalam pengetahuan selanjutnya.

\section{DAFTAR PUSTAKA}

Andi. “Pengertian Rental DVD". Yogyakarta: Andi offset, 2001

Budi Permana, “SQL Server 2000”, PT. Elex Media Komputindo, Jakarta, 2002
Daryanto, "Belajar Komputer Visual Basic", CV. Yrama Widya, 2003.

De Marco, "Analisa Sistem Informasi", Pustaka Binaman Presindo, Jakarta, 1996.

Davis GB, "Sistem Manajemen dan Informasi, "Pustaka Binaman, Jakarta, 2001.

Jogiyanto, H.M, "Analisa dan Desain Sistem Informasi," Andi Offset, Yogyakarta, 2001.

Kasmoni, "Visual Basic 6.0 Untuk Orang Awam", CV. Maxikom, Palembang, 2003.

McLeod R, Jr, "Sistem Informasi Manajemen", PT. Prenhallindo, Jakarta, 1998.

McLeod R, Jr, "Database Management System (DBMS)", PT. Prenhallindo, Jakarta, 2000. 